\title{
NOTAS TAXONÔMICAS EM XYRIS L. (XYRIDACEAE)
}

\author{
Maria das Graças Lapa Wanderley' \\ Maria das Graças Sajo ${ }^{2}$
}

Recebido em 4/11/96. Aceito em 30/12/96.

RESUMO - (Notas taxonômicas em Xyris L. (Xyridaceae)). São propostas alterações nomenclaturais e taxonômicas em Xyris, status novum e dois novos sinônimos.

Palavras-chave: Xyridaceae, Xyris, status novo, novos sinônimos

ABSTRACT - (Taxonomic notes in Xyris L. (Xyridaceae)). Nomenclatural and taxonomic changes are proposed in Xyris; one new status and two new synonym.

Key-words: Xyridaceae, Xyris, new status, new synonym

\section{Introdução}

O estudo que as autoras vem realizando com espécies de Xyris dos campos rupestres brasileiros tem demonstrado a importância de associar a morfologia externa e a anatomia foliar e do escapo floral no esclarecimento dos problemas de circunscrição de algumas destas espécies (Wanderley 1992; Sajo et al. 1995). X. obtusiuscula A. Nilsson, X. trachyphylla Mart. eX. diamantinae Malme, tratadas no presente trabalho, são espécies taxonomicamente próximas e freqüentes nos campos rupestres de Minas Gerais, onde vivem simpatricamente. Estas espécies caracterizam-se pela placentação central-livre, sendo que as duas primeiras apresentam sépalas laterais concrescidas cerca da metade, folhas e escapos florais conspicuamente transverso-rugulosos até ásperos e margens das bainhas densamente ciliadas, enquanto $X$. diamantinae distingue-se facilmente destas espécies pelas sépalas concrescidas apenas na base, folhas e escapos geralmente lisos e margens das bainhas glabras.X. trachyphylla, apesar de ser muito semelhante a $X$. obtusiuscula, pode ser reconhecida especialmente pelo maior porte da planta, pela presença de mancha verde-acinzentada na superfície dorsal das

\footnotetext{
Instituto de Botânica. C.P. 4005, CEP 01061-970. São Paulo, SP, Brasil. Bolsista de Produtividade do CNPq.

2 IBUNESP- C.P. 199. CEP 13506-900. Rio Claro, SP, Brasil. Bolsista de Produtividade do CNPq.
} 
brácteas, lâminas achatadas e bainha foliar arroxeada a castanho-escura. Xyris obtusiuscula tem menor porte, as brácteas são em geral sem manchas, as lâminas variam de cilíndricas a subcilíndricas e a bainha foliar é negra (Wanderley 1992).

Diferentes padrões anatômicos da folha e do escapo floral foram apresentados por Wanderley (1992) para as espécies de Xyris da Serra do Cipó. Dentre estas espécies, $X$. obtusiuscula, $X$. trachyphylla e $X$. diamantinae apresentam diferentes padrões de vascularização foliar, variando quanto ao número de feixes vasculares e de séries, polos de xilema e camadas de fibras vasculares no feixe vascular. Estas características foram fundamentais no esclarecimento da delimitação das espécies que fazem parte de um complexo, que inclui, além das espécies anteriormente referidas, $X$. longiscapa A. Nilsson, muito próxima de $X$. diamantinae, cujas diferenças são o maior número de flores por inflorescência e coloração alva das brácteas na primeira e menor número de flores e coloração avermelhada das margens das brácteas na segunda.

\section{Resultados e discussão}

O amplo estudo das espécies no campo e a análise de várias coleções de herbário, permitiram, apesar de reforçar a proximidade taxonômica entre elas, reconhecê-las separadamente, apresentando, entretanto, as seguintes mudanças taxonômicas e nomenclaturais:

Xyris itatiayensis (Malme) Wand. \& Sajo, stat. nov.

X. obtusiuscula A. Nilsson var. itatiayensis Malme, Ark. Bot. 13 (13): 89. 1913.

Typus: Brasil. Rio de Janeiro: Pico do Itatiaia, Pedra Assentada, Dúsen 144, 19/V/ 1902. (Lectotypus S, Isolectotypus R, US, MO!).

Material adicional examinado: Minas Gerais: Santana do Riacho, Serra do Cipó, col. Wanderley \& Sajo 1963; 1966; 1972 (SP); Wanderley \& Giulietti CFSC 11519 (SP).

Analisando-se várias coleções de Xyris obtusiuscula var. itatiayensis, procedentes da Serra do Cipó, Minas Gerais e do Pico do Itatiaia, Rio de Janeiro, inclusive do lectotypus (Dúsen 144), observou-se uma ampla variação tanto da parte vegetativa como da inflorescência deste táxon (Fig. 1-4). Nos materiais do Rio de Janeiro, as brácteas da inflorescência são em geral de ápice arredondado e com carena inconspícua (Fig. 4), caráter menos freqüente nos exemplares da Serra do Cipó, onde se observa uma transição do ápice arredondado, longo-acuminado, até patente e carenado (Fig. 2-3). A princípio, estas diferenças sugeriram a indicação de uma nova espécie para os materiais da Serra do Cipó, mas o estudo detalhado das populações mostrou uma continuidade deste caráter, levando a conclusão de se tratar de um mesmo táxon, sendo proposta a elevação à categoria de espécie. As principais diferenças entre Xyris itatiayensis e X. obtusiuscula são as folhas achatadas (Fig. 1 e 16), densa pilosidade das brácteas e sépalas, bem como bainhas castanho-escuras a arroxeadas na primeira. 


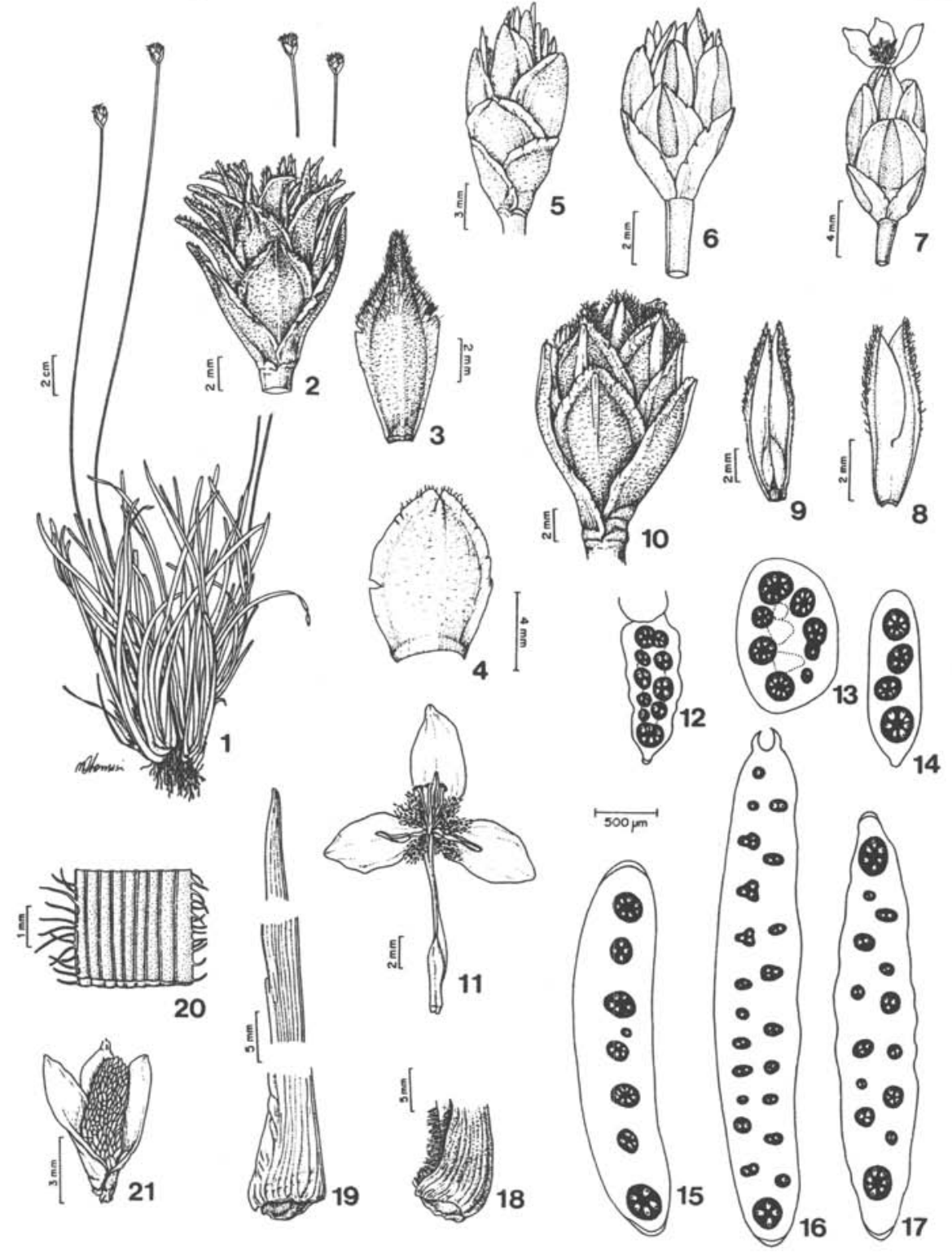

Figuras 1-4: X̣̂ris itatiayensis: 1 :hábito; 2:espiga; 3-4: brácteas estéreis. 5-6: X. obtusiuscula $(6:=X$. montivaga var. microstuchya). 7-8: $X$. trachyphylla: 7: espiga; 8: sépalas laterais concrescidas. 9-11: $X$. diamantinae; 9: sépalas concrescidas apenas na base; 10: espiga; 11: flor. 12-17: diagramas de cortes transversais da lâmina foliar do limbo na porção mediana: 12-14: X. obtusiuscula; 15: X. diamantinae; 16: $X$. itatiayensis; 17: X. trachyphylla. 18: base da bainha foliar de X. itatiayensis. 19: base, meio e ápice da folha de $X$. diamantinae. 20: X. trachyphylla: segmento da lâmina foliar. $21: X$. obtusiuscula: ovário mostrando placentação central-livre. 
Em $X$. obtusiuscula as folhas são largo-elípticas, cilíndricas a subcilíndricas (Fig. 12-14), as bainhas são geralmente negras e as espigas apresentam em geral brácteas com ápice ereto, arredondado ou agudo (Fig. 5 e 6). Observou-se que o padrão de vascularização foliar bisseriado com predominância de feixes vasculares tripolares (Fig. 16) em X. itatiayensis diferencia esta espécie de X. obtusiuscula, cujos feixes vasculares são distintamente menos numerosos e em geral multipolares (Fig. 12-14). $O$ padrão vascular da folha de $X$. itatiayensis é mais semelhante ao de $X$. trachyphylla (Fig. 17), tendo sido, no entanto, observadas várias situações intermediárias, assim como entre as demais espécies deste grupo, que analisadas em conjunto com outras características morfológicas, sugerem a possível formação de híbridos naturais entre elas (Wanderley 1992).

Xyris obtusiuscula A. Nilsson, Kongl. Svenska Vetenskapsakad. Handl. 1892. 24(14): 47. Typus: Brasil. Minas Gerais, Sellow B- 1087. (Holotypus B!).

$X$. montivaga Kunth var. microstachya A. Nilsson, Kongl. Svenska Vetenskapsakad. Handl. 24 (14): 49.1892. Syn. nov. Typus: Brasil. São Paulo: campos da Bocaina. A. Glaziou 8001, 11/II/1876.(Holotypus P).

$X$. trachyphylla Mart. var. microstachya A. Nilsson

Material adicional examinado: Xyris obtusiuscula $(=X$. montivaga var. microstachya): Minas Gerais: Santana do Riacho, Serra do Cipó, Wanderley \& Sajo 1965; 1967;1973 (SP).X. obtusiuscula: H.C. Lima 381 (RB); Kral \& Lopes 72979 (SP); São Paulo, Shepherd \& Shepherd 12889 (SP). X. trachyphylla: Wanderley CFSC 9283; 9288 (SP).

O grande polimorfismo de Xyris trachyphylla, que apresenta brácteas com mancha conspícua na face dorsal (Fig. 7), levou à criação de várias variedades para esta espécie. Entretanto, com base nos estudos morfológicos deste táxon e observando diferentes populações no campo (Wanderley CFSC 9283, 9288), verificou-se que, apesar desta característica ser de grande valia para o reconhecimento da mesma, em alguns indivíduos, especialmente os mais velhos, ela pode estar ausente ou ocorrer de forma inconspícua, como em X. obtusiuscula (Kral \& Lopes 72979) (Fig. 5). Chama-se a atenção desta forma para o cuidado que se deve ter em relação ao uso deste caráter, que apesar de importante, não deve ser usado isoladamente. Por estas características $X$. montivaga var. microstachya, com representante na Serra do Cipó (Wanderley \& Sajo 1965; 1967; 1973) e em São Paulo (Shepherd \& Sheperd 12889), foi sinonimizada em X. trachyphylla (Smith \& Downs 1968). No presente trabalho foram aceitas as variedades já propostas por estes autores para $X$. trachyphylla, exceto a var. microstachya. Esta variedade caracteriza-se pelas folhas cilíndricas (Fig. 14) a subcilíndricas (Fig. 13), com bainhas negras e brácteas com mancha conspícua, fazendo parte da amplitude de variação de $X$. obtusiuscula, diferindo essencialmente do padrão geral desta espécie, apenas pela presença de mancha na face dorsal das brácteas, característica esta presente em $X$. trachyphylla 
(Fig. 7) e geralmente ausente na maioria dos indivíduos típicos de $X$. obtusiuscula (Kral \& Lopes 72979) (Fig. 5). A princípio, pela relativa escassez de materiais com esta característica, pensou-se na possibilidade de se tratar de um híbrido entre $X$. trachyphylla e $X$. obtusiuscula, com folhas cilíndricas a subcilíndricas (Fig. 13-14) como esta última e as brácteas como a da primeira (Fig. 6-7). Entretanto, estas variações foram consideradas parte de $X$. obtusiuscula, não sendo propostas divisões infraespecíficas para a mesma. O padrão de vascularização foliar observado para os materiais considerados como X. trachyphylla var. microstachya (Fig. 1314) é semelhante ao de $X$. obtusiuscula (Fig. 12), com feixes vasculares multipolares, dispostos em duas séries nos exemplares de folhas elípticas (Fig. 12), unisseriados nas de folhas subcilíndricas (Fig. 14) e em círculos, naqueles de folhas cilíndricas (Fig. 13). Por outro lado este padrão é bastante distinto de X. trachyphylla, que apresenta como $X$. itatiayensis, feixes vasculares em geral tripolares e bisseriados (Fig. 17), além das folhas achatadas (Fig. 20) e com superfície transverso-rugulosa.

Xyris diamantinae Malme, Ark. Bot. 22A (15): 5.1929.Typus: Brasil. Minas Gerais: Milho Verde, cerca de Diamantina (Tejuco), A. Saint- Hilaire s.n., 1817 (Holotypus $\mathrm{P} !)$.

X. celiae L.B. Sm. \& Downs, Arquivo Bot. Est. São Paulo, n. ser. 4 (2): 26. 1966. Syn. nov. Typus: Brasil. Minas Gerais: Serra de Lavras Novas, ca. $2 \mathrm{~km}$ ao sul de Ouro Preto. B. Maguire, M. Magalhães \& C.K. Maguire 49303. (Holotypus US, Isotypus NY!)

Material adicional examinado: Minas Gerais: Santana do Riacho, Serra do Cipó, Wanderley \& Sajo 1978; Wanderley CFSC 5613; 5495.

Analisando-se os materiais-tipos de Xyris diamantinae e de X. celiae e de várias populações destes táxons verificou-se que se tratam da mesma espécie, apesar de apresentarem as variações extremas da espécie, como tamanho da planta e da espiga e mancha das brácteas conspícua, inconspícua até ausente (Fig. 10). Não havendo dúvida que estas variações fazem parte da amplitude morfológica da espécie, as mesmas foram sinonimizadas. O padrão vascular de $X$. diamantinae é distinto das demais espécies deste grupo, sendo semelhante ao de $X$. longiscapa com numerosos feixes vasculares multipolares. Estas duas espécies diferenciam-se essencialmente pelo menor número de flores por inflorescência e margens das brácteas com tricomas avermelhados em $X$. diamantinae, enquanto $X$. longiscapa apresenta inflorescência com maior número de flores por inflorescência e margens das brácteas com tricomas alvos (Wanderley 1992).

Estudos anatômicos das espécies estudadas e de outras, consideradas dentro do mesmo complexo, estão sendo paralelamente realizados, acreditando-se que os dados a serem obtidos contribuirão para a elucidação dos problemas taxonômicos destes táxons. 


\section{Referências bibliográficas}

Sajo, M. G.; Wanderley, M.G.L. \& Carvalho, L.M. 1995. Caracterização anatômica foliar para 14 espécies de Xyris L. (Xyridaceae) da Serra do Cipó, MG, Brasil. Acta bot. bras. 9 (1): 101-114.

Smith, L.B. \& Downs, R. 1968. Xyridaceae. In: F.C. Hoehne, (ed.), Flora brasilica 9 (2): 1-209.

Wanderley, M. G. L. 1992. Estudos taxonômicos no gênero Xyris L. (Xyridaceae) da Serra do Cipó, Minas Gerais, Brasil. Tese de Doutorado. Instituto de Biociências da Universidade de São Paulo. 